\title{
Field electron energy spectroscopy of alumina-supported platinum adatoms
}

\author{
A. Cörper, G. Bozdech, N. Ernst ${ }^{*}$, T. Klüner ${ }^{* *}$, and H.-J. Freund \\ Fritz-Haber-Institut der Max-Planck-Gesellschaft, Faradayweg 4-6, 14195 Berlin, Germany
}

Received 12 April 2005, revised 19 June 2005, accepted 23 June 2005

Published online 22 August 2005

PACS 68.37.Vj, 68.47.Gh, 73.20.Hb, 73.22.-f, 79.70.+q, 81.65.Mq

Field electron energy spectroscopy and density functional calculations have been employed to characterize electronic properties of single Pt-adatoms deposited on a thin alumina film. For $\mathrm{Pt} / \mathrm{Al}_{2} \mathrm{O}_{3} / \mathrm{NiAl}(110)$ strong current enhancements were measured about $1.4 \mathrm{eV}$ below the Fermi energy. No features were observed for clean $\mathrm{Al}_{2} \mathrm{O}_{3} / \mathrm{NiAl}(110)$ and $\mathrm{Pt} / \mathrm{NiAl}(110)$ in the accessible energy range. As an explanation we propose a resonance tunneling mechanism involving an occupied electronic state of the Pt adatom close to the Fermi level.

(C) 2005 WILEY-VCH Verlag GmbH \& Co. KGaA, Weinheim

\section{Introduction}

In view of applications ranging from catalysis to optics the characterization of oxide-supported and embedded nanoparticles has been an ongoing challenge to experiment and theory [1]. In particular, bulk oxide and thin oxide films supporting small particles, such as $\mathrm{Ag}, \mathrm{Au}, \mathrm{Cu}, \mathrm{Pd}$ and $\mathrm{Pt}$ have been acting as model systems for heterogeneous catalysis [2]. Experimental and theoretical model studies have recently addressed single, oxide supported adatoms such as $\mathrm{Pd} / \mathrm{MgO}(100)$, catalyzing the $\mathrm{CO}$-oxidation and the acetylene trimerization [3]. It has been suggested that the nature of the chemical bond of a Pd adatom on a vacancy site on $\mathrm{MgO}$ plays a crucial role for the catalytic action. Theoretical characterizations of oxideadatom interactions have been and are still in the focus of improved density functional and quantum chemical methods [4]. However, quantitative comparisons with experimental data on adatom ensembles, like heat of adsorption, surface diffusion activation energy $\left(E_{\text {Diff }}\right)$ and local density of electronic states (LDOS) remain doubtful because such measurements usually average over structurally and electronically different objects [2]. Theoretical results can be tested by applying experimental techniques on individual oxide supported adatoms as attempted for Pt and Pd [5-7]. Using field ion microscopy (FIM) we have measured a value for $E_{\mathrm{Diff}}$ for a single Pt adatom deposited on the defect-free region of an alumina film prepared on a [110]-oriented NiAl tip [8,9]. The experimental result, $0.29 \pm 0.03 \mathrm{eV}$ is at least a factor of two smaller than the value calculated for the system $\mathrm{Pt} / \mathrm{Al}_{2} \mathrm{O}_{3} / \mathrm{Al}(111)$ challenging more theoretical efforts [10]. Recently, scanning tunneling spectroscopy (STS) has been employed to characterize individual Pd atoms $\left(4 d^{10}\right)$ adsorbed on $\mathrm{Al}_{2} \mathrm{O}_{3} / \mathrm{NiAl}(110)$ [7]. Strongly site dependent tunneling resonances at $3 \mathrm{eV}$ above the Fermi energy, $E_{\mathrm{F}}$ have been observed and were tentatively assigned to an empty Pd $5 \mathrm{sp}$ orbital. No features below $E_{\mathrm{F}}$ have been found in the energy range accessible to STS. Using field electron energy spectroscopy (FES) we have detected current enhancement factors up to 400 at approximately $1.4 \mathrm{eV}$ below $E_{\mathrm{F}}$ for individual Pt atoms $\left(5 d^{9} 6 s^{1}\right)$ adsorbed on $\mathrm{Al}_{2} \mathrm{O}_{3} / \mathrm{NiAl}(110)$ described as follows. We discuss our FES data in view of earlier reported [11] and our calculated LDOS results for $\mathrm{Pt} / \mathrm{Al}_{2} \mathrm{O}_{3}[12-16]$.

\footnotetext{
* Corresponding author: e-mail: ernst@fhi-berlin.mpg.de, Phone: ++49-(0)30-8413-4180, Fax: ++49-(0)30-8413-4101

** Current address: Carl von Ossietzky Universität Oldenburg, Institut für Reine und Angewandte Chemie, AG Theoretische Physikalische Chemie, Carl-von-Ossietzky Str. 9-11, 26129 Oldenburg, Germany
} 


\section{Methods}

In present experiments, a well ordered alumina island (diameter about $20 \mathrm{~nm}$ ) has been prepared on the thermally enlarged (110) facet of a [110] oriented NiAl field emitter tip [5, 6, 9]. Neon-FIM controlled field evaporation revealed removal of approximately two alumina layers in agreement with earlier measurements of the film thickness $(0.5 \mathrm{~nm})$ [5]. Unlike in recent STM studies [17] FIM does not reveal the atomic corrugation of the alumina surface [Fig. 1]. In spite of that, FIM observations of Pt adatom positions were feasible and indicated an approximately hexagonal arrangement of Pt binding sites [5]. In contrast, individual Pd adatoms could not be imaged.

As described earlier [6,9] an electron beam heated evaporator allowed to deposit Pt atoms on the specimen at approximately $40 \mathrm{~K}$ without discernable formation of Pt cluster. Probe-hole FIM and FES investigations (using an electrostatic, hemispherical mirror-analyzer) have been performed in a UHV chamber at specimen temperatures of about $40 \mathrm{~K}$. To achieve sufficient counting rates the energy resolution was set to about $0.4 \mathrm{eV}$ with accessible energies ranging to $1.5 \mathrm{eV}$ below $E_{\mathrm{F}}$. From total energy distributions, $j(E)$ we derive energy dependent enhancement factors $R(E)=j_{\text {meas }}(E) / j_{\text {theo }}(E)[18]$. Here, $j_{\text {meas }}$ is a measured curve after Pt deposition and $j_{\text {theo }}$ is a calculated distribution based on a free-electron gas approximation for the field emission process. It includes the apparatus function [19] obtained from fits to measured distributions without Pt [Fig. 1]. For adatom-metal surface complexes, the quantity $(R-1)$ is proportional to the LDOS times a field and energy dependent function [18]. In line with these earlier approaches we consider effects of the applied electrostatic field such as level shift, broadening and voltage drop in the oxide layer when comparing $R(E)$-data with the calculated (field-free) LDOS of aluminasupported Pt adatoms [11, 12].

\section{Results and discussion}

To compare experimental results for clean $\mathrm{NiAl}(110) \& \mathrm{Al}_{2} \mathrm{O}_{3} / \mathrm{NiAl}(110)$ before and after deposition of Pt we have carried out FIM and FES measurements [Fig. 1]. The two FIM images on the bottom display the boundary of the $\mathrm{NiAl}(110)$ facet, prepared by low temperature field evaporation and enlarged by

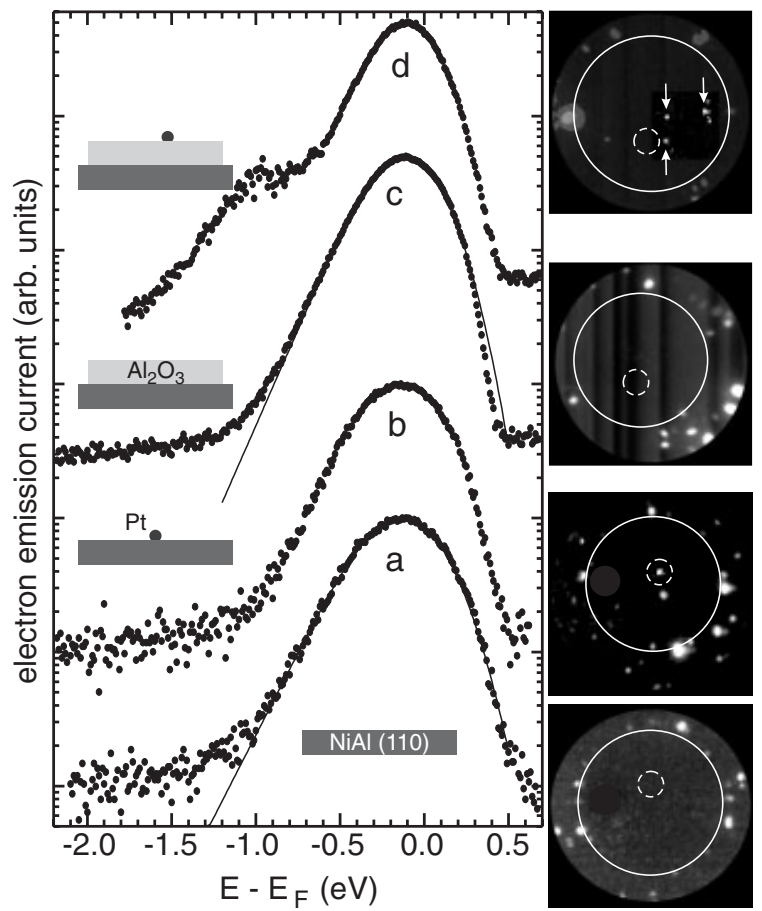

Fig. 1 Semi-log plots of FES data for (a) clean $\mathrm{NiAl}(110)$ and (b) Pt adatoms deposited thereon. Fits (full lines in (a) and (c)) include the FWHM, $\Delta E$ of the Gaussian transmission function according to Ref. [19]. For field strength, work function and temperature following values were used for fits in (a) and (c) (in brackets): $F=4.2(3.4) \mathrm{V} / \mathrm{nm}, \Phi=5.0(4.4) \mathrm{eV}$, $T=36$ (39) $\mathrm{K}, \Delta E=0.46(0.42) \mathrm{eV}$. Upon Pt deposition (d) on $\mathrm{Al}_{2} \mathrm{O}_{3} / \mathrm{NiAl}(110)$ a feature appears. Thereafter, FIM verifies probe hole position (image on top, dashed circle) relative to $\mathrm{Pt}$ adatoms (arrows). Big circles indicate boundaries of uppermost atomic planes (diameter $\sim 20 \mathrm{~nm}$ ). 
subsequent annealing. Plane diameters are indicated by solid white lines (approximately $20 \mathrm{~nm}$ ). Dashed circles indicate positions of the probe-hole, projected on the (110) facet, marking the geometrically probed area during FES. The effectively probed area is somewhat larger. Diagrams on the left in Fig. 1 show energy distributions plotted on a semi-log scale: (a) measured for clean $\mathrm{NiAl}(110)$ including a fit for the enhancement analysis [19] and (b) after deposition of two Pt adatoms. Upon deposition of Pt on $\mathrm{NiAl}(110)$ there is no noticeable difference in spectral shape in the accessible energy range to approximately $1.5 \mathrm{eV}$ below $E_{\mathrm{F}}$. FES of clean $\mathrm{NiAl}(110)$ does not reveal any feature at $0.8 \mathrm{eV}$ below $E_{\mathrm{F}}$, earlier identified as a $d$-like surface state [20]. It is conceivable that our approach is not sensitive enough to detect such a presumably weak feature. For $\mathrm{Pt} / \mathrm{NiAl}(110)$ the absence of additional features in FES, to approximately $1.5 \mathrm{eV}$ below $E_{\mathrm{F}}$ indicates that there is no pronounced influence of an adatom induced resonance. Theoretical results for $\mathrm{Au} / \mathrm{NiAl}(110)$ suggest that bonding of gold atoms to $\mathrm{NiAl}(110)$ induces a splitting and a shift of the Au6s state [21]. The higher energy, $s$-like adatom resonance was calculated to $1.91 \mathrm{eV}$ above $E_{\mathrm{F}}$ (including a Stark shift) and was in good agreement with STS data for unoccupied states. The occupied energy level was calculated to $3 \mathrm{eV}$ below $E_{\mathrm{F}}$ and not accessible to STS. Assuming a similar splitting and downshift of the occupied Pt resonance on NiAl(110) may explain missing features in our energy distributions.

In contrast to $\mathrm{Pt} / \mathrm{NiAl}(110)$ FES results are markedly different if alumina supported $\mathrm{Pt}$ is examined [Fig. 1(c, d)]. Spectral data for $\mathrm{Al}_{2} \mathrm{O}_{3} / \mathrm{NiAl}(110)$ equal the ones measured for $\mathrm{NiAl}(110)$ confirming our earlier results indicating an $\mathrm{Al}_{2} \mathrm{O}_{3}$ film transparent for electrons field emitted from filled NiAl states close to $E_{\mathrm{F}}[5,9]$. After Pt deposition a new feature is detected [Fig. 1(d)]. The FIM image, taken thereafter reveals (i) that there are three Pt adatoms (albeit at weak image intensities, indicated by arrows) and (ii) that the probe hole did not cover a Pt adatom during FES. In spite of that, electrons emitted with favourably directed momenta, essentially from the adatom right next to the dashed circle, cause the spectral feature.

To substantiate our observations we present results of another experiment in Fig. 2. After preparation of a fresh $\mathrm{Al}_{2} \mathrm{O}_{3}$-island there is no feature on the low energy side of the FES spectra [Fig. 2(a)]. Upon Pt dosing the FES measurement [Fig. 2(b)] reveals a second, most abundant peak at $1.1 \mathrm{eV}$ below $E_{\mathrm{F}}$ in addition to the peak from the alumina coated NiAl substrate and at the same value as for the feature in Fig. 1(d). Due to the low Pt coverage degree, estimated to $1 / 1000$ of a monolayer, the feature must be caused by an individual Pt adatom. To support our conclusion we carried out FES measurements at $40 \mathrm{~K}$

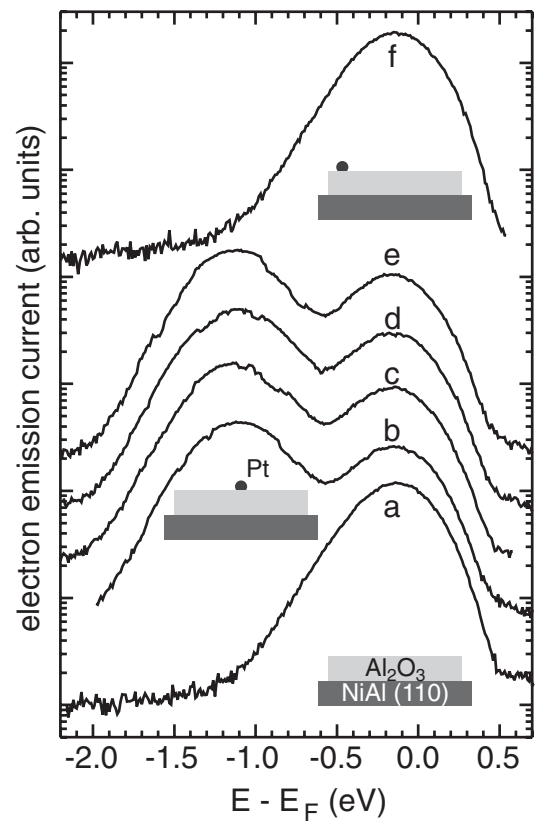

Fig. 2 Semi-log plots of spectroscopic results obtained at about $40 \mathrm{~K}$ (a) for clean $\mathrm{Al}_{2} \mathrm{O}_{3} / \mathrm{NiAl}(110)$ and (b) after Pt deposition. After $20 \mathrm{~s}$ heating cycles at zero field to $90 \mathrm{~K}$ (c), $100 \mathrm{~K}$ (d) and $110 \mathrm{~K}$ (e) the Pt-feature governs the spectra at $1.1 \mathrm{eV}$ below $E_{\mathrm{F}}$. Heating to $120 \mathrm{~K}$ for $20 \mathrm{~s}$ causes disappearance of feature (f) indicating Pt surface diffusion out of probed area sketched in the cartoons. 


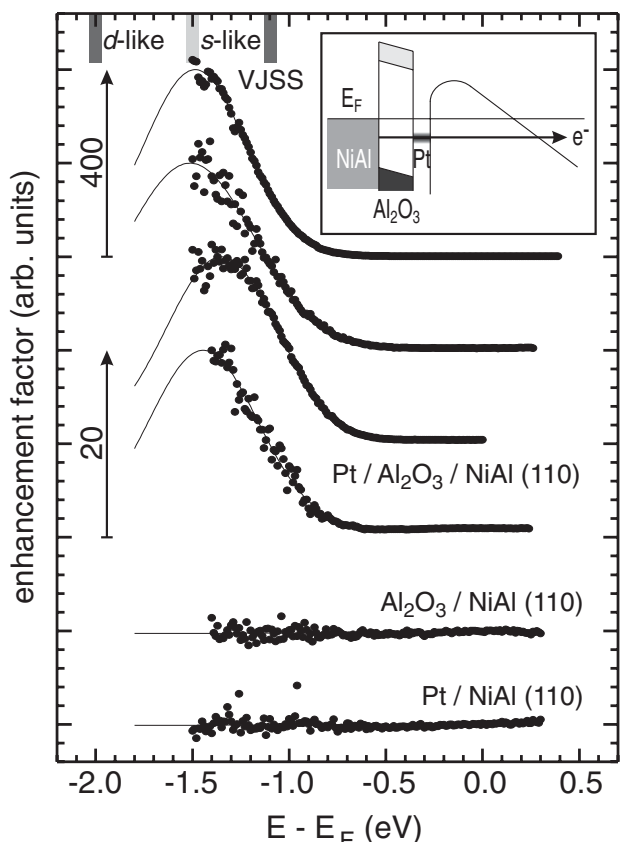

Fig. 3 Enhancement curves, $R(E)$ and calculated (field free) LDOS results for $\mathrm{Pt} / \mathrm{Al}_{2} \mathrm{O}_{3}$ (bars on top). For $\mathrm{Pt} / \mathrm{Al}_{2} \mathrm{O}_{3} / \mathrm{NiAl}(110)$ Gaussian fits to measured $R(E)$ data (dots) reveal maxima around $-1.4 \mathrm{eV}$ (at lower energy compared to $\mathrm{Pt}$ induced features in energy distributions, $j(E)$ in Figs. 1 and 2). Bar labeled VJSS shows peak-position of total LDOS for $\mathrm{Pt} / \mathrm{Al}_{2} \mathrm{O}_{3}$ reported in Ref. [11]. Positions of $d$ - and $s$-like peaks (dark \& light bars) are from this work. The energy diagram (inset) illustrates resonance tunneling in an applied electrostatic field.

after (field-free) heating cycles closely below and above the surface diffusion onset temperature $(100 \mathrm{~K})$ for $\mathrm{Pt} / \mathrm{Al}_{2} \mathrm{O}_{3} / \mathrm{NiAl}(110)[8,9]$. Heating to 90,100 and $110 \mathrm{~K}(20 \mathrm{~s})$ does not affect FES features in Fig. 2(c-e). However, heating to $120 \mathrm{~K}$ causes the feature to disappear [Fig. 2(f)]. The schematic drawings in Fig. 2 illustrate our explanation based on Monte Carlo (MC) simulations on the mobility of alumina-supported Pt [9, 22-24]. Below $120 \mathrm{~K}$ and at $20 \mathrm{~s}$ heating times estimated root-mean-square (RMS) displacements are smaller than the radius of the probed area [Fig. 2(c-e)]. At $120 \mathrm{~K}$ the calculated RMS displacement value is larger than the radius of the probed area and MC-simulations suggest frequent adatom excursions up to the boundary of the oxide island. Since spectral shapes of the low energy feature do not change much upon heating we conclude that they are caused by an individual $\mathrm{Pt}$ adatom adsorbed on similar sites of the alumina film.

To interpret our observations we discuss current enhancement data, $R(E)$ and calculated LDOS results [Fig. 3]. For $\mathrm{NiAl}(110)$ (not shown) and $\mathrm{Pt} / \mathrm{NiAl}(110)$ spectral shapes agree with calculated data from the Fowler-Nordheim model [18]. Between 0 and $-1.5 \mathrm{eV}$ [Fig. 3, bottom] we do not observe enhancements possibly caused by a $\mathrm{NiAl}(110)$ surface state or a Pt adatom resonance [7, 20]. Also, for the clean alumina film, $R(E)$ data do not show any features, e.g., due to a defect or interface state in agreement with photoemission and STS results. However, upon deposition of $\mathrm{Pt}$ adatoms on $\mathrm{Al}_{2} \mathrm{O}_{3} / \mathrm{NiAl}(110)$ analyses of four experimental runs reveal the following effects. $R(E)$ increases distinctly below $-0.5 \mathrm{eV}$ reaching maximum values between 20 (from data in Fig. 1) and 400 (from Fig. 2) at 1.3 to $1.5 \mathrm{eV}$ below $E_{\mathrm{F}}$. Intrinsic full-widths-at-half-maximum (from deconvolved fits) range between 0.4 and $0.5 \mathrm{eV}$, somewhat larger than measured for $\mathrm{Pd} / \mathrm{Al}_{2} \mathrm{O}_{3} / \mathrm{NiAl}(110), 0.35 \mathrm{eV}$ at about $3 \mathrm{eV}$ above $E_{\mathrm{F}}$ [7].

Our observations can be understood by a resonance tunneling mechanism involving a filled adatom level, i.e. a Pt induced LDOS maximum at approximately $1 \mathrm{eV}$ below $E_{\mathrm{F}}$. [Fig. 3 inset]. A similar process has been invoked to interpret field electron emission microscopy observations on Au clusters supported on a less ordered alumina layer on a W-tip [25]. Within an Oppenheimer scheme, tunneling enhancements have been calculated from the ratio of the squares of resonant to non-resonant tunneling matrix elements for $s$ - and $d$-like states of $\mathrm{Ba} / \mathrm{W}[26]$. Accordingly one expects smaller tunneling probabilities and smaller FWHMs for $d$-like $(\approx 0.1 \mathrm{eV})$ than for $s$-like $(\approx 1 \mathrm{eV})$ adatom resonances. Following this early theoretical work [26] our FWHM value $(0.45 \mathrm{eV})$, measured for $\mathrm{Pt} / \mathrm{Al}_{2} \mathrm{O}_{3} / \mathrm{NiAl}(110)$ could indicate an $s d$-like state. 
The measured emission-current enhancements can be compared, at least qualitatively with earlier [11] and our recently calculated results for $\mathrm{Pt} / \mathrm{Al}_{2} \mathrm{O}_{3}$ using a density functional approach [12]. The earlier approach gave a maximum LDOS at $-1.1 \mathrm{eV}$ with essentially $d$ like character [Fig. 3 on top, right black bar labelled VJSS]. We find a strong maximum of a $d$-like LDOS at $-2.0 \mathrm{eV}$ and an $s$-like contribution at $-1.5 \mathrm{eV}$ albeit an order of magnitude smaller. At present, quantitative comparisons are not possible because of several reasons such as: (i) differences of adsorption geometries in experiment and theory and (ii) effects of the applied electrostatic field. Field effects to be considered are: a voltage drop in the alumina layer leading to a downward shift of about $200 \mathrm{meV}$ and a Stark shift, possibly by several hundred $\mathrm{meV}$. Effects such as field induced polarization of the adatom oxide complex may also lead to a shift and broadening of the resonance [18]. As mentioned, STS did not detect an adatom resonance for $\mathrm{Pd} / \mathrm{Al}_{2} \mathrm{O}_{3} / \mathrm{NiAl}(110)$ between 0 and $2 \mathrm{eV}$ below $E_{\mathrm{F}}$ although theory predicts peaks in the Pd induced LDOS in this energy range $[14,16]$. It is conceivable that different final state wave functions (tip vs. continuum states) imply a lower sensitivity of the STS approach compared to FES for the systems under study.

\section{Conclusions}

In conclusion, we have measured field-emission current enhancements induced by individual Pt adatoms, supported on a well ordered alumina film, with peak values as high as 400 at about $1.4 \mathrm{eV}$ below $E_{\mathrm{F}}$ and intrinsic FWHMs of 0.4 to $0.5 \mathrm{eV}$. We have proposed a resonance tunneling mechanism involving an occupied Pt-adatom state in an electrostatic field of approximately $4 \mathrm{~V} / \mathrm{nm}$ in line with (field free) DFTmodel calculations showing $s$ - and $d$-derived peaks in the Pt-induced LDOS just below $E_{\mathrm{F}}$. Future theoretical efforts should improve the modelling of the alumina film. It appears also desirable to carry out high sensitivity STS measurements on heavier transition metal adatoms such as Pt deposited on the alumina film.

Acknowledgements We are grateful to the "Fonds der Chemischen Industrie" for support. We would also like to thank Professor Gert Ehrlich for providing us with a program for MC-simulations of surface diffusion. Helpful discussions with Professor Paul Bagus and Dr. Niklas Nilius are gratefully acknowledged.

\section{References}

[1] G. Ertl, H. Knözinger, and J. Weitkamp (eds.), Handbook of Heterogeneous Catalysis (Wiley-VCH, Weinheim, 1997).

A. F. Carley, P. R. Davies, G. J. Hutchings, and M. S. Spencer (eds.), Surface Chemistry and Catalysis (Kluwer Academic, New York, 2002).

[2] C. T. Campbell, Surf. Sci. Rep. 227, 1 (1997).

C. R. Henry, Surf. Sci. Rep. 31, 231 (1998).

M. Bäumer and H.-J. Freund, Prog. Surf. Sci. 61, 127 (1999).

U. Diebold, Surf. Sci. Rep. 48, 53 (2003).

D. W. Goodman, J. Catal. 216, 213 (2003).

[3] S. Abbet, U. Heiz, H. Häkkinen, and U. Landman, Phys. Rev. Lett. 86, 5950 (2001)

S. Abbet, A. M. Ferrari, L. Giordiano, G. Pacchioni, H. Häkkinen, U. Landman, and U. Heiz, Surf. Sci. 514, 249 (2002).

[4] G. Pacchioni, Surf. Sci. 520, 3 (2002).

[5] N. Ernst, B. Duncombe, G. Bozdech, M. Naschitzki, and H.-J. Freund, Ultramicroscopy 79, 231 (1999).

[6] N. Nilius, A. Cörper, G. Bozdech, N. Ernst, and H.-J. Freund, Prog. Surf. Sci. 67, 99 (2001).

[7] N. Nilius, T. M. Wallis, and W. Ho, Phys. Rev. Lett. 90, 46808 (2003).

[8] H.-J. Freund et al., phys. stat. sol. (a) 187, 257 (2001); in: Surface Chemistry and Catalysis, edited by A. F. Carley, P. R. Davies, G. J. Hutchings, and M. S. Spencer (Kluwer Academic, New York, 2002), pp. $103-$ 145.

[9] A. Cörper, Dissertation, Technical University Berlin 2003 , http://www.edocs.tu-berlin.de/diss/2003/coerper_alexander.htm.

[10] A. Bogicevic and D. R. Jennison, Phys. Rev. Lett. 82, 4050 (1999). 
[11] C. Verdozzi, D. R. Jennison, P. A. Schultz, and M. P. Sears, Phys. Rev. Lett. 82, 799 (1999).

[12] DFT calculations have been performed using a commercial version of the CASTEP code [13] whereby the $\mathrm{Al}_{2} \mathrm{O}_{3}(0001)$ surface was modelled by a slab consisting of nine oxygen layers [14]. The gradient-corrected PW91 exchange correlation functional [15] has been used and a plane wave cut-off of $260 \mathrm{eV}$ turned out to be sufficient. Calculated adsorption energies for a palladium atom were found to be $-1.42 \mathrm{eV}$ (on top of $\mathrm{O}$ ) and $-1.24 \mathrm{eV}$ (threefold hollow) in agreement with recently reported theoretical results [16]. The corresponding results for a platinum atom were found to be $-1.59 \mathrm{eV}$ and $-1.36 \mathrm{eV}$, respectively [14].

[13] M. C. Payne, M. P. Teter, D. C. Allan, T. A. Arias, and J. D. Joannopoulos, Rev. Mod. Phys. 64, 1045 (1992); CASTEP was provided by Accelrys Inc., San Diego, Californa.

[14] T. Klüner, unpublished.

[15] J. P. Perdew, J. A. Chevary, S. H. Vosko, K. A. Jackson, M. R. Pederson, D. J. Singh, and C. Fiolhais, Phys. Rev. B 46, 6671 (1992)

[16] J. R. B. Gomes, F. Illas, N. C. Hernandez, A. Márquez, and J. F. Sanz, Phys. Rev. B 65, 125414 (2002).

[17] G. Ceballos, Z. Song, J. I. Pascual, H.-P. Rust, H. Conrad, M. Bäumer, and H.-J. Freund, Chem. Phys. Lett. 359, 41 (2002). M. Kulawik, N. Nilius, H.-P. Rust, and H.-J. Freund, Phys. Rev. Lett. 91, 256101 (2003)

[18] A. Modinos, Field, Thermionic, and Secondary Electron Emission Spectroscopy (Plenum Press, New York, 1984).

[19] R. D. Young and C. E. Kuyatt, Rev. Sci. Instrum. 39, 1477 (1968).

[20] K. Hojrup Hansen, T. Worren, S. Stempel, E. Laegsgaard, M. Bäumer, H.-J. Freund, F. Besenbacher, I. Stensgaard, Phys. Rev. Lett. 83, 4120 (1999).

[21] N. Nilius, T. M. Wallis, M. Persson, and W. Ho, Phys. Rev. Lett. 90, 196103 (2003).

[22] MC-simulations, based on a random walk approach were performed for a hexagonal lattice (fcc 111) assuming single jumps between neighbor (fcc)-sites [23]. A diffusion barrier value of $0.29 \mathrm{eV}$ was used, derived from measurements of the surface diffusion onset temperature [24] for $\mathrm{Pt} / \mathrm{Al}_{2} \mathrm{O}_{3} / \mathrm{NiAl}(110)[8,9]$.

[23] J. D. Wrigley, M. E. Twigg, and G. Ehrlich, J. Chem. Phys. 93, 2885 (1990).

[24] G. L. Kellogg, Surf. Sci. Rep. 21, 1 (1994).

[25] J. Plšek and Z. Knor, Appl. Surf. Sci. 171, 157 (2001).

[26] J. W. Gadzuk, Phys. Rev. B 1, 2110 (1970). 